\title{
Effect of ultrasound-guided transversus abdominis plane block with rectus sheath block on patients undergoing laparoscopy- assisted radical resection of rectal cancer: a randomized, double-blind, placebo- controlled trial
}

\author{
Min Liang ${ }^{1}, X_{i a} X v^{1}$, Chunguang Ren ${ }^{1}$, Yongxing Yao ${ }^{2}$ and Xiujuan Gao ${ }^{1 *}$ (D)
}

\begin{abstract}
Background: Many patients complain of pain following laparoscopic surgery. Clinicians have used ultrasoundguided posterior transversus abdominis plane block (TAPB) and rectus sheath block (RSB) for multimodal analgesia after surgery. We investigated the analgesic effects of US-guided posterior TAPB with RSB on postoperative pain following laparoscopy-assisted radical resection of early-stage rectal cancer.

Methods: Seventy-eight adults scheduled for laparoscopy-assisted radical resection of rectal cancer were enrolled in this double-blind placebo-controlled trial. Patients were randomized into 3 groups: the TR Group underwent USguided bilateral posterior TAPB ( $40 \mathrm{~mL}$ 0.33\% ropivacaine) with RSB (20 mL 0.33\% ropivacaine); the T Group underwent US-guided bilateral posterior TAPB alone; and the Control Group received saline alone. All patients also had access to patient-controlled intravenous analgesia (PCIA) with sufentanil. The primary outcome was postoperative sufentanil consumption at $0-24,24-48$, and $48-72 \mathrm{~h}$. The secondary outcomes were postoperative pain intensity and functional activity score at rest and while coughing for the same three time periods, intraoperative medication dosage, use of rescue analgesia, recovery parameters, and adverse effects.

Results: The three groups had no significant differences in baseline demographic and perioperative data, use of intraoperative medications, recovery parameters, and adverse effects. The TR group had significantly lower postoperative use of PCIA and rescue analgesic than in the other two groups $(P<0.05)$, but the Control Group and T Group had no significant differences in these outcomes.
\end{abstract}

Conclusions: Postoperative US-guided posterior TAPB with RSB reduced postoperative opioid use in patients following laparoscopy-assisted radical resection of rectal cancer.

Trial registration: The trial was registered with chictr.org (ChiCTR2000029326) on January 25, 2020.

Keywords: Ultrasound, Transversus abdominis plane, Rectus sheath, Sufentanil, Rectal cancer

\footnotetext{
*Correspondence: xiujuan_gao@126.com

'Department of Anesthesiology, Liaocheng People's Hospital, Liaocheng, Shandong, People's Republic of China

Full list of author information is available at the end of the article
}

C C The Author(s). 2021 Open Access This article is licensed under a Creative Commons Attribution 4.0 International License, which permits use, sharing, adaptation, distribution and reproduction in any medium or format, as long as you give appropriate credit to the original author(s) and the source, provide a link to the Creative Commons licence, and indicate if changes were made. The images or other third party material in this article are included in the article's Creative Commons licence, unless indicated otherwise in a credit line to the material. If material is not included in the article's Creative Commons licence and your intended use is not permitted by statutory regulation or exceeds the permitted use, you will need to obtain permission directly from the copyright holder. To view a copy of this licence, visit http://creativecommons.org/licenses/by/4.0/ The Creative Commons Public Domain Dedication waiver (http://creativecommons.org/publicdomain/zero/1.0/) applies to the data made available in this article, unless otherwise stated in a credit line to the data. 


\section{Background}

Colorectal cancer is one of the most common tumors and is a leading cause of cancer-related deaths worldwide [1]. Because of the increasing incidence of rectal cancer and the improved rates of recovery after surgery, laparoscopy-assisted radical resection of early-stage rectal cancer has become more common [2]. Although laparoscopy reduces the size of the operative incision, many patients complain of postoperative pain. Opioid analgesia is traditionally provided following a laparoscopic abdominal operation [3]. However, adverse effects from opioid analgesia (postoperative nausea and vomiting [PONV]), may increase the duration of the hospital stay and reduce patient satisfaction [4].

There has been an increasing use of ultrasound (US) technologies, and US-guided peripheral nerve block has become a fundamental part of postoperative multimodal analgesia. US-guided posterior transversus abdominis plane block (TAPB) and US-guided rectus sheath block (RSB) have been used during abdominal surgeries, and previous studies indicated that they provide potent analgesic effects [5-7]. Currently, there is limited evidence in the literature to support the use of US-guided posterior TAPB combined with RSB.

The aim of this study is to evaluate the efficacy of USguided posterior TAPB with or without RSB in postoperative pain management for patients following laparoscopyassisted radical resection of rectal cancer.

\section{Methods}

\section{Patients}

This randomized, double-blinded, placebo-controlled trial was performed following approval of the ethics committee of the Liaocheng People's Hospital. The trial was registered with chictr.org before enrollment of the first participant (Trial registration: ChiCTR, ChiCTR2000029326. Registered 25 January 2020, http://www.chictr.org.cn), and written informed consent was obtained from all patients prior to enrollment. All findings are reported in accordance with the Consolidated Standards of Reporting Trials (CONSORT) guidelines.

All enrolled patients were scheduled to undergo laparoscopic radical resection (Dixon operation) following diagnosis of clinical stage I or II rectal cancer at the Liaocheng People's Hospital between January 2020 and June 2020. The inclusion criteria were age between 35 and 70 years, ability to understand and use the pain assessment method, and physical status of I to III according to the American Society of Anesthesiologists (ASA). The exclusion criteria were history of allergy to local anesthetics, history of opioid abuse, history of treatment for another cancer, refusal to use patient-controlled analgesia (PCA), need for resection of another organ(s) in addition to the rectum, history of previous abdominal surgery, and preoperative intestinal obstruction requiring emergency surgery.

\section{Randomization and blinding}

Two days before surgery, random numbers that were generated by SPSS were used to assign equal numbers of eligible participants to one of the three groups. The TR Group received US-guided bilateral posterior TAPB with $40 \mathrm{~mL}$ of $0.33 \%$ ropivacaine and RSB with $20 \mathrm{~mL}$ of $0.33 \%$ ropivacaine; the $\mathrm{T}$ Group received US-guided bilateral posterior TAPB with $40 \mathrm{~mL}$ of $0.33 \%$ ropivacaine and RSB with $20 \mathrm{~mL}$ of $0.9 \%$ normal saline; the Control Group received US-guided bilateral posterior TAPB with $40 \mathrm{~mL}$ of $0.9 \%$ normal saline and RSB with $20 \mathrm{~mL}$ of $0.9 \%$ normal saline. Patients in all groups also received postoperative patient controlled intravenous analgesia (PCIA) (see below for details). Randomized results were kept in a sealed envelope and relayed to an independent nurse anesthetist who prepared the drug or placebo on the morning of the operation. The remainder of the clinicians, the main anesthesiologist, and the anesthesiologist who administered the TAPB were all blinded to the group allocations.

\section{General anesthesia and monitoring}

All patients underwent regular fasting for 8 to $12 \mathrm{~h}$ without any preoperative medication. Before the induction of anesthesia, intravenous (IV) fluids were administered at a rate of $10 \mathrm{~mL} / \mathrm{kg} / \mathrm{h}$, and the heart rate, continuous invasive arterial blood pressure, pulse oxygen saturation, bispectral index (BIS), and nasopharyngeal temperature were continuously monitored using a multifunction monitor (Philips IntelliVue MP50, Boeblingen, Germany). For all patients, anesthesia was induced with IV propofol $(2.0 \mathrm{mg} / \mathrm{kg})$, fentanyl $(3 \mu \mathrm{g} / \mathrm{kg})$, and cisatracurium $(0.15 \mathrm{mg} /$ $\mathrm{kg}$ ), according to standard general anesthesia guidelines set by the institute. Tracheal intubation was performed after muscle relaxation. Anesthesia was maintained using inhalational sevoflurane and remifentanil. To maintain a BIS value of 40 to 60 and a mean arterial pressure within $20 \%$ of the baseline value, sevoflurane and remifentanil were continuously adjusted. Ephedrine was administrated if the intraoperative blood pressure was more than 20\% below the baseline, and atropine was administered if the heart rate was lower than $50 \mathrm{bpm}$. IV cisatracurium $(0.03 \mathrm{mg} / \mathrm{kg})$ was added hourly until the end of the operation.

\section{Surgery}

Laparoscopic incision and trocar insertion were performed by adopting the five hole method. The five incisions were: (i) on the supraumbilical site; (ii) 2 finger widths inside the right anterior superior iliac spine; (iii) 3 to $4 \mathrm{~cm}$ above the cross point of the right clavicular midline and the umbilicus intersection; (iv) at the mid- 
point of the line between the left anterior superior iliac spine and umbilicus; and (v) 2 finger widths above the symphysis pubis, which could be expanded to 5 or $6 \mathrm{~cm}$ for specimen removal (Fig. 1). The pneumoperitoneum was established with carbon dioxide, and pressure was 12 to $14 \mathrm{mmHg}$ (1.36 to $1.58 \mathrm{kpa}$ ). The operation was performed according to the specifications and principles of laparoscopic and radical resection of rectal cancer (i.e. total mesorectal resection (TEM), thorough lymphadenectomy, and tumor eradication). The Dixon operation was used based on tumor location.

\section{US-guided TAPB and RSB}

After removal of the tracheal tube, TAPB was performed immediately by a qualified anesthesiologist using US guidance (SonoSite S-Nerve Ultrasound System) and a broadband (4 to $13 \mathrm{MHz}$ ) linear array ultrasound probe. For the posterior approach, the probe was placed transversely in the midaxillary line between the iliac crest and the costal margin [8]. Then, the probe was moved outward and the needle was inserted when the TAP was identified. When the tip of the needle was in the TAP, 2 $\mathrm{mL}$ of normal saline was injected to adjust its position. Then, $40 \mathrm{~mL}$ of $0.33 \%$ ropivacaine was administered to the TR Group and T Group, and $40 \mathrm{~mL}$ of $0.9 \%$ normal saline was administered to the Control Group (Fig. 2).

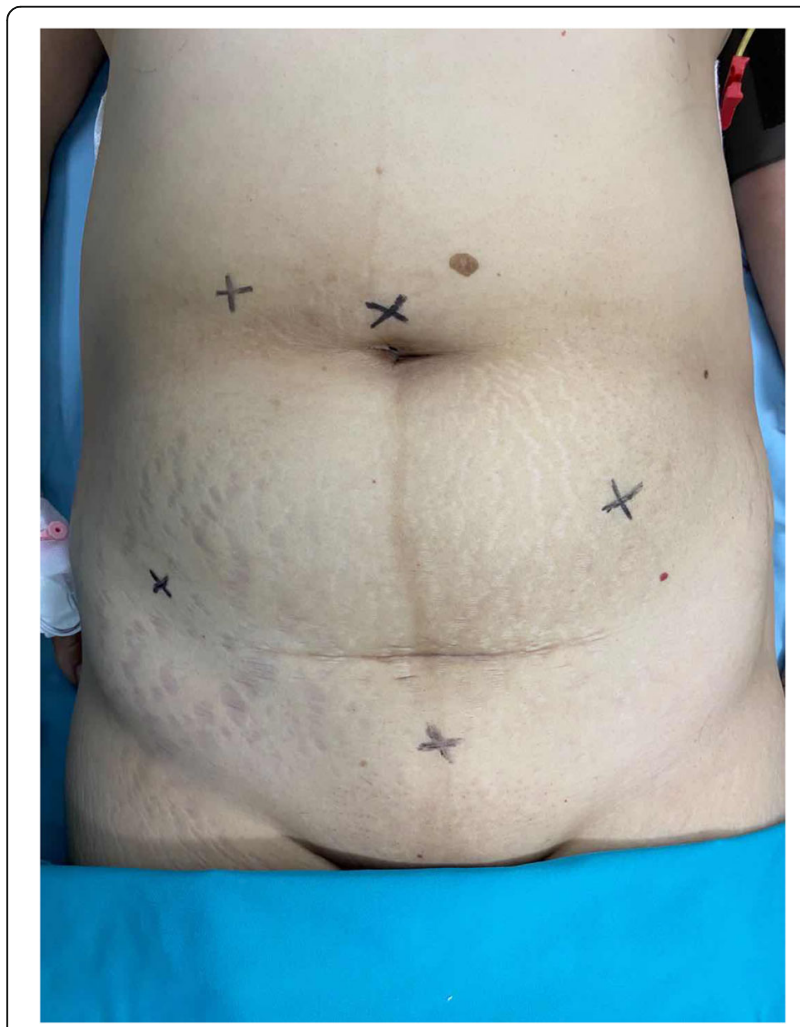

Fig. 1 Laparoscopic incision and trocar insertion using the five hole method

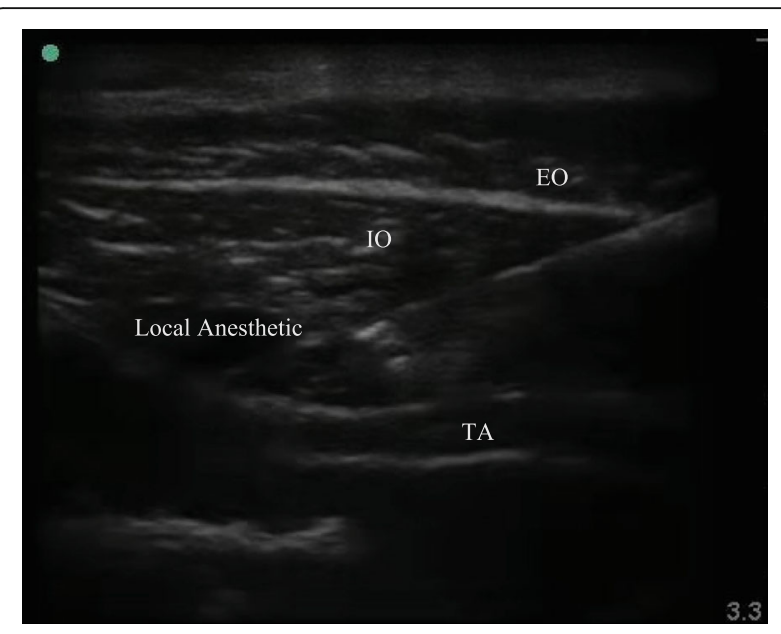

Fig. 2 TAP block

Next, RSB was performed on both sides of the linea alba under US-guidance [7]. For the RSB, the probe was placed transversely on the rectus abdominis and the needle was inserted using US guidance until the tip was in the plane between the rectus abdominis and the posterior sheath of the rectus abdominis [9]. Patients in the TR Group received $20 \mathrm{~mL}$ of $0.33 \%$ ropivacaine, and patients in the $\mathrm{T}$ Group and Control Group received 20 $\mathrm{mL}$ of $0.9 \%$ normal saline. The procedure was divided into 3 or 4 injection sites on the left and right sides of the surgical site to prevent the rectus abdominis tendon from blocking the spread of the drug (Fig. 3).

\section{Postoperative care}

Sufentanil was used for PCIA, which was initiated in the post-anesthesia care unit (PACU). The PCIA regimen consisted of $300 \mathrm{~mL}$ of $0.8 \mu \mathrm{g} / \mathrm{mL}$ sufentanil, with a bolus dose of $2 \mathrm{~mL}$, a lockout time of $5 \mathrm{~min}$ with no background infusion, and a 4-h maximum limit of

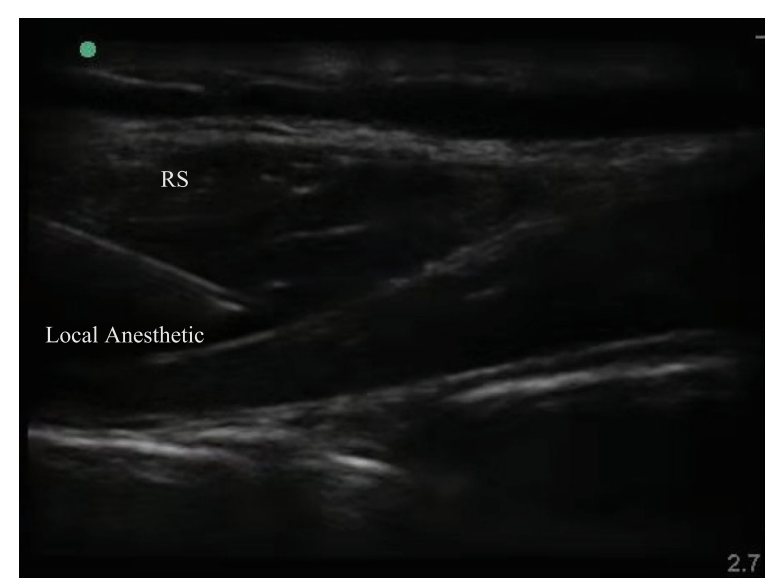

Fig. 3 RS block 
$30 \mathrm{~mL}(24 \mu \mathrm{g})$. The aim of PCIA was to control pain intensity based on a numerical rating scale (NRS) at rest of 4 or less. The NRS is an objective pain intensity assessment tool that has a scale of 0 to 10 , in which 0 indicates no pain and 10 indicates the worst pain possible. Any patient whose NRS value at rest was above 4 was given a loading dose of $4 \mathrm{~mL}$ $(3.2 \mu \mathrm{g})$ sufentanil, and had a $4 \mathrm{~h}$ maximum limit of $40 \mathrm{~mL}$. For patients with insufficient analgesia or sufentanil intolerance, additional rescue analgesia was given (30 mg IV ketorolac).

\section{Data collection}

Sufentanil-based PCIA was used in all groups with the same regimen for $72 \mathrm{~h}$ after surgery. The cumulative PCA usage during three time period after the operation ( 0 to $24 \mathrm{~h}, 24$ to $48 \mathrm{~h}$, and 48 to $72 \mathrm{~h}$ ) was the primary outcome, and was recorded by a blinded member of the acute pain service (APS) team. The secondary outcomes were postoperative pain intensity on the NRS and functional activity score (FAS) at rest and during coughing after 24,48 , and $72 \mathrm{~h}$ [10]. The FAS is a subjective pain intensity assessment tool that uses grades $\mathrm{A}, \mathrm{B}$, and $\mathrm{C}$. Grade A indicates that functional activity is not limited by pain; grade $B$ indicates that functional activity is moderately limited because of pain; and grade $\mathrm{C}$ indicates that functional activity is severely limited because of pain. Use of intraoperative medications and rescue analgesia were recorded. In addition, the time to first flatus, defecation, oral intake, and discharge were recorded. All adverse effects possibly due to sufentanil, such as nausea, vomiting, pruritus, respiratory depression, and dizziness, were recorded.

\section{Statistical analysis}

The sample size was based on the initial pilot data, in which the means \pm standard deviations of sufentanil use during the $24 \mathrm{~h}$ period after surgery were recorded. (Control Group: $84 \pm 47 \mu \mathrm{g}$, T Group: $80 \pm 37 \mu \mathrm{g}$, TR Group: $41 \pm 16 \mu \mathrm{g})$. Based on a power of $95 \%$ and a significance level of 5\%, 20 patients per group were necessary. Assuming a 30\% dropout rate, a minimum of 26 patients per group were enrolled.

Statistical analysis was performed using SPSS 16.0 (SPSS Inc. Chicago, IL). The Kolmogorov-Smirnov test was used to assess the distributions of variables, and homogeneity of variance was determined using Levene's test. Data with normal distributions are presented as means and standard deviations and data with nonnormal distributions are presented as medians and interquartile ranges. Categorical data are presented as number (n) and percentage (\%). ANOVA tests were used to

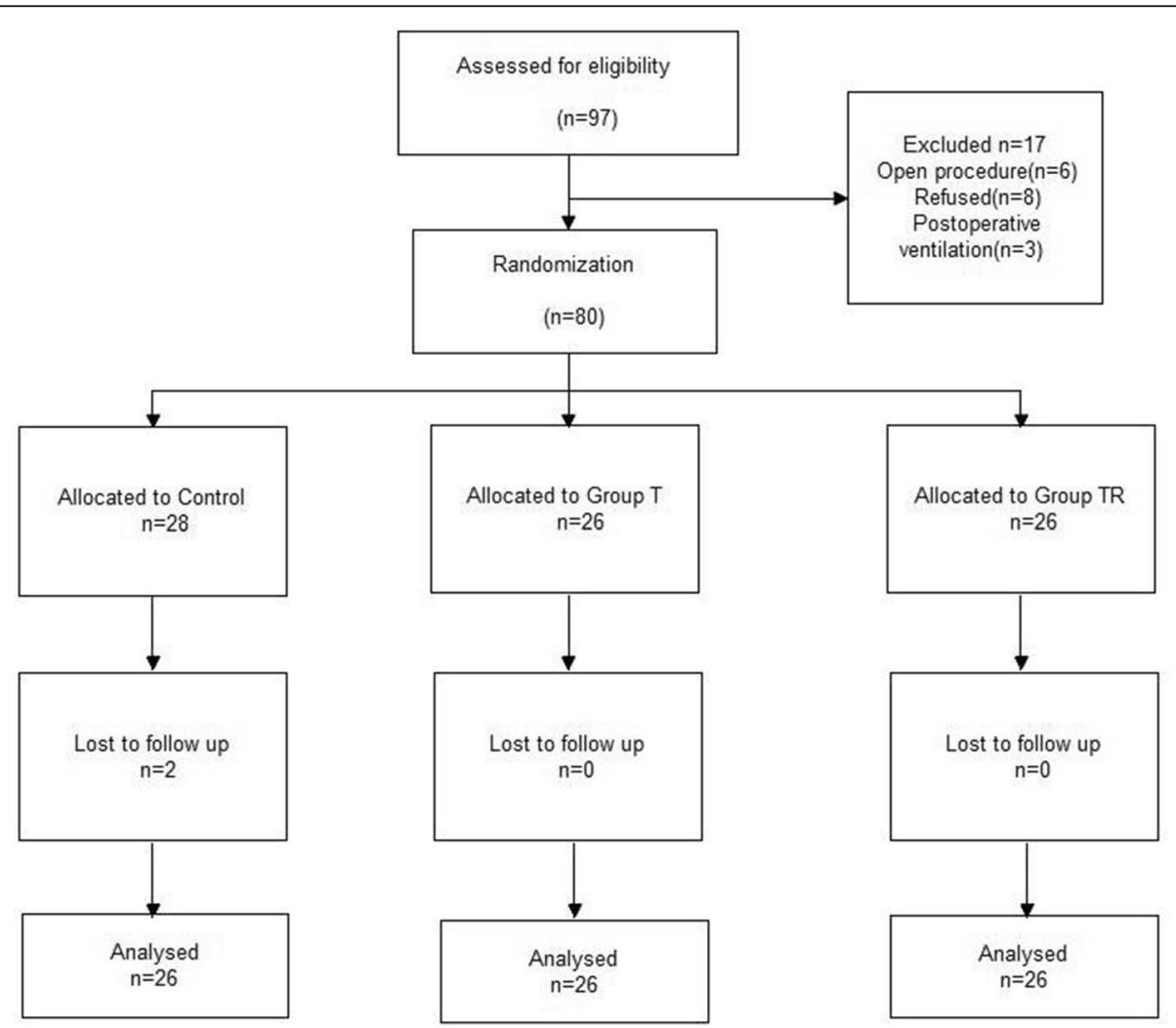

Fig. 4 Disposition of eligible patients with stage I/II rectal cancer 
Table 1 Demographic and perioperative characteristics of the three groups

\begin{tabular}{|c|c|c|c|c|}
\hline Variable & Group C $(n=26)$ & Group T $(n=26)$ & Group TR $(n=26)$ & $P$ \\
\hline Age (years) & $60.6 \pm 8.2$ & $61.5 \pm 8.2$ & $61.5 \pm 8.1$ & 0.899 \\
\hline Male/Female (n) & $13 / 13$ & $16 / 10$ & $18 / 8$ & 0.362 \\
\hline BMI $\left(\mathrm{kg} / \mathrm{m}^{2}\right)$ & $23.6 \pm 2.2$ & $23.4 \pm 2.0$ & $23.9 \pm 2.6$ & 0.697 \\
\hline ASA I/II/III (n) & $1 / 21 / 4$ & $1 / 18 / 7$ & $0 / 19 / 7$ & 0.691 \\
\hline Clinical Stage I/II (n) & $14 / 12$ & $10 / 16$ & $13 / 13$ & 0.513 \\
\hline Blood loss (mL) & $108.0 \pm 65.4$ & $131.9 \pm 30.1$ & $131.5 \pm 26.6$ & 0.092 \\
\hline Urine $(\mathrm{mL})$ & $398.0 \pm 226.5$ & $301.9 \pm 197.7$ & $380.8 \pm 183.9$ & 0.199 \\
\hline Surgery duration (min) & $174.6 \pm 50.2$ & $195.2 \pm 46.0$ & $181.7 \pm 42.7$ & 0.275 \\
\hline Fluid infusion (mL) & $1465.4 \pm 386.7$ & $1511.5 \pm 436.3$ & $1536.5 \pm 437.6$ & 0.833 \\
\hline Propofol (mg) & $120.0 \pm 21.9$ & $119.6 \pm 17.5$ & $128.3 \pm 18.3$ & 0.197 \\
\hline Fentanyl (mg) & $0.27 \pm 0.08$ & $0.29 \pm 0.08$ & $0.29 \pm 0.09$ & 0.765 \\
\hline Cisatracurium (mg) & $20.1 \pm 3.7$ & $21.0 \pm 3.2$ & $19.8 \pm 3.3$ & 0.412 \\
\hline Remifentanil (mg) & $0.38 \pm 0.13$ & $0.46 \pm 0.12$ & $0.42 \pm 0.10$ & 0.065 \\
\hline Sevoflurane (\%) & $2.47 \pm 0.37$ & $2.44 \pm 0.37$ & $2.32 \pm 0.40$ & 0.336 \\
\hline Atropine (mg) & $2(7.7 \%)$ & $3(11.5 \%)$ & $4(15.4 \%)$ & 0.690 \\
\hline Ephedrine (mg) & $5(19.2 \%)$ & $3(11.5 \%)$ & $2(7.7 \%)$ & 0.448 \\
\hline
\end{tabular}

Variables are presented as mean \pm SD or number of patients $(n)$

Data were analyzed using a one-way analysis of variance or chi-square test. ASA American Society of Anesthesiology, BMI body mass index

compare data with normal distributions. Non-parametric tests were used to compare data with non-normal distributions; the Kruskal-Wallis $\mathrm{H}$ method was used for overall comparisons, and the Mann-Whitney U method was used to compare differences between groups. Categorical variables were analyzed using the $\chi^{2}$ test or Fisher's exact test. $P$ values below .05 were considered significant.

\section{Results}

Our assessments indicated that 97 patients were eligible for enrollment (Fig. 4) Seventeen patients were excluded and 2 patients were lost to follow-up. We therefore analyzed data of the remaining 78 patients. The 3 groups had no significant differences in demographic parameters, operation conditions, and fluid and anesthetic administration $(P>0.05$, Table 1$)$. In addition, none of the patients required a change of analgesic.

The TR Group used significantly less postoperative sufentanil than the Control Group and Group T at 0 to $24 \mathrm{~h}(37.5 \pm 17.38 \mu \mathrm{g}$ vs. $80.0 \pm 46.13 \mu \mathrm{g}$ vs. $74.8 \pm 51.10$, $P<0.01), 24$ to $48 \mathrm{~h}(29.0 \pm 24.28 \mu \mathrm{g}$ vs. $56.3 \pm 31.31 \mu \mathrm{g}$ vs. $57.6 \pm 32.86, P<0.01)$, and 48 to $72 \mathrm{~h}(19.4 \pm 15.84 \mu \mathrm{g}$ vs. $47.6 \pm 35.41 \mu \mathrm{g}$ vs. $42.0 \pm 26.24, P<0.01$ ) (Fig. 5). The Control Group and T Group had no significant difference in use of postoperative sufentanil $(P>0.05$, Fig. 5).

The postoperative NRS pain scores at rest and during coughing were low in all groups at $24 \mathrm{~h}, 48 \mathrm{~h}$, and $72 \mathrm{~h}$, and there were no significant differences among the three groups $(P>0.05$, Fig. 6$)$. The postoperative FASs were also favorable in all groups at $24 \mathrm{~h}, 48 \mathrm{~h}$, and $72 \mathrm{~h}$, and there were no significant differences $(P>0.05$, Table 2).

The TR Group required less rescue analgesia than the Control Group and the T Group $(P<0.05$, Table 3$)$, but there were no significant differences between the Control Group and the T Group $(P>0.05$, Table 3). The three groups had no significant differences in any of the measured recovery parameters $(P>0.05$, Table 4$)$ and no differences in the incidences of sufentanil-associated adverse effects $(P>0.05$, Table 5$)$. None of the patients experienced respiratory depression $(P>0.05$, Table 5$)$.

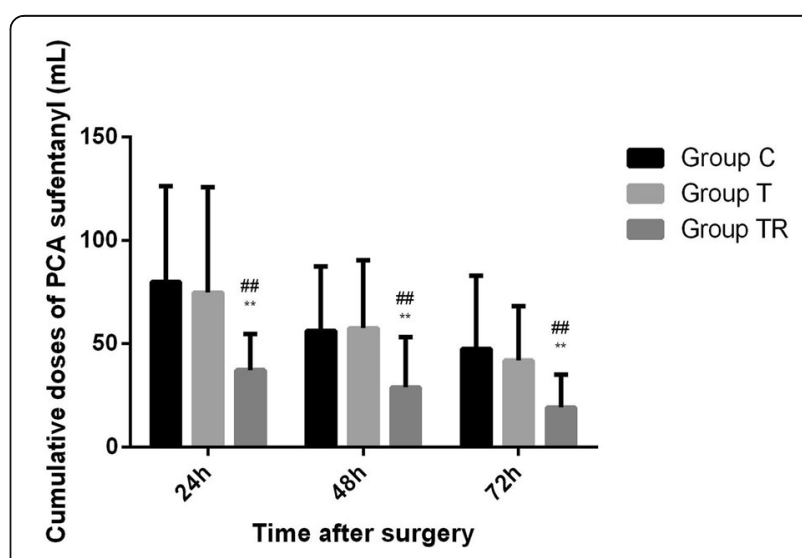

Fig. 5 Postoperative sufentanil use in the three groups. ${ }^{*} P<.01$ vs. Control Group, \#\#P<.01 versus. T Group 


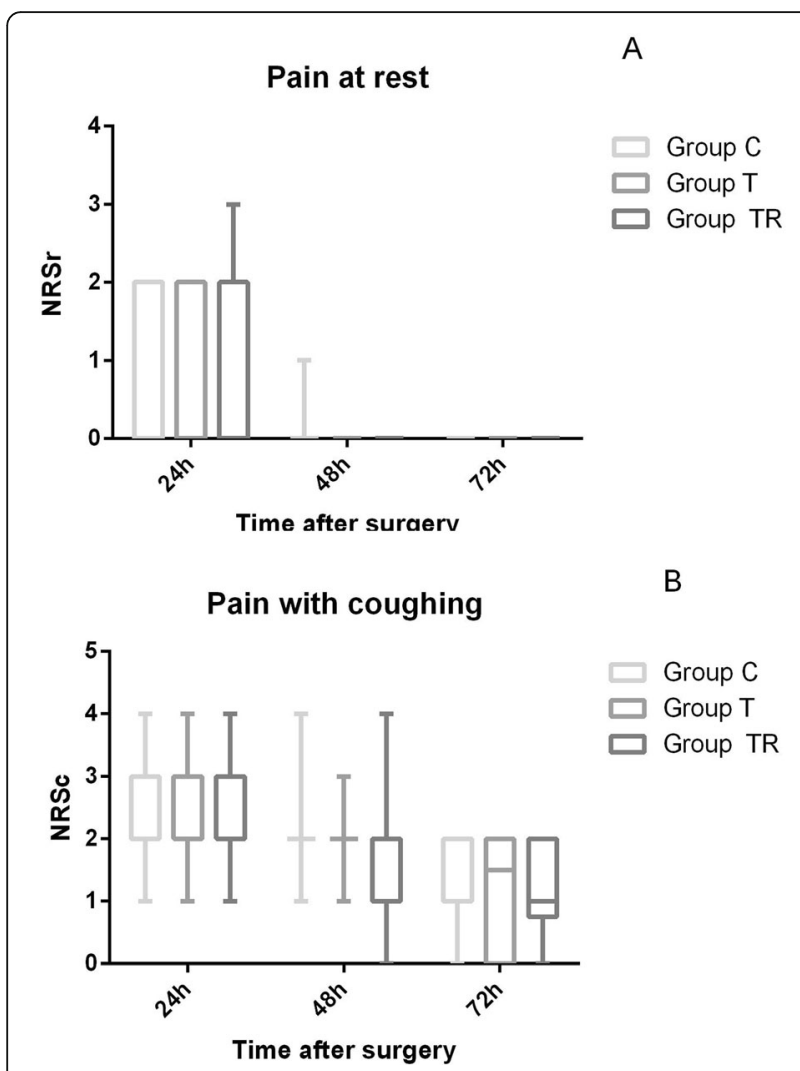

Fig. 6 a Postoperative pain scores at rest in the three groups (NRS = numerical rating scale). $\mathbf{b}$ Postoperative pain scores with coughing in the three groups

\section{Discussion}

There are two main findings in this research. First, patients who received laparoscopy-assisted radical resection of early-stage rectal cancer had significantly reduced use of postoperative PCIA and rescue analgesia when they received US-guided TAPB with RSB. Second, there were no significant differences in the use of postoperative PCIA for groups who received US-guided posterior TAPB with RSB and TAPB alone.
A laparoscopic approach for colorectal surgery has many benefits for patients, and should now be considered as a standard treatment [11-13]. Nevertheless, postoperative pain is still the main factor affecting the recovery of these patients [14], and adequate postoperative analgesia remains essential $[15,16]$. Multimodal analgesia, including US-guided peripheral nerve block, has proven safety and effectiveness for pain management [17-19]. For example, a retrospective study of 43 patients undergoing laparoscopic colectomy showed that the combination of US-guided TAP and RSB significantly reduced the use of continuous intravenous fentanyl after surgery [20]. Another prospective study of 60 patients showed that TAP $(20 \mathrm{~mL}$ of $0.375 \%$ ropivacaine) significantly reduced the use of fentanyl by patients undergoing hand-assisted laparoscopic colon surgery, and also reduced the recovery time of bowel function and the duration of hospitalization [21]. Khaled Yassen et al. observed 55 patients with cirrhosis who received liver surgery and found that repeated US-guided TAPB and RSB $(0.2 \mathrm{~mL} / \mathrm{kg}$ of $0.25 \%$ bupivacaine, every $8 \mathrm{~h}$ for $48 \mathrm{~h}$ ) significantly reduced the use of opioids after surgery [19]. Khaled Abdelsalam et al. observed 40 patients undergoing upper abdominal surgery (hepatectomy or Whipple procedure) and found that US-guided bilateral TAPB and RSB ( $20 \mathrm{~mL}$ of bupivacaine $0.25 \%$ for each) significantly reduced the use of opioids [22]. Another prospective study of 126 patients who received laparoscopic liver resection showed that US-guided bilateral TAP and RSB significantly reduced the patient-reported pain-VAS score, the dosage of ondansetron, and hospital stay [23]. Lili Xu et al. found that US-guided TAPB plus RSB prolonged the analgesia time and reduced postoperative pain in high-risk elderly patients who received emergency abdominal surgery [24]. Other studies of single-incision gynecological laparoscopic surgery reported that bilateral TAPB combined with RSB provided better results than TAPB alone $[25,26]$. In addition, Tak Kyu Oh et al. examined patients undergoing laparoscopic colorectal cancer surgery and reported that TAP did not significantly reduce postoperative pain or opioid use [27]. The conclusions of these many studies are consistent with our findings.

Table 2 Postoperative functional activity scores in the three groups ( $n$ )

\begin{tabular}{|c|c|c|c|c|c|}
\hline & Variable & $\begin{array}{l}\text { Group C }(n=26) \\
\text { C/B/A }\end{array}$ & $\begin{array}{l}\text { Group T }(n=26) \\
\text { C/B/A }\end{array}$ & $\begin{array}{l}\text { Group TR }(n=26) \\
\text { C/B/A }\end{array}$ & $P$ \\
\hline \multirow[t]{3}{*}{ FAS } & $24 \mathrm{~h}$ & $0 / 4 / 22$ & $0 / 2 / 24$ & $0 / 3 / 23$ & 0.686 \\
\hline & $48 \mathrm{~h}$ & $0 / 2 / 24$ & $0 / 1 / 25$ & 0/0/26 & 0.353 \\
\hline & $72 \mathrm{~h}$ & $0 / 1 / 25$ & 0/0/26 & $0 / 0 / 26$ & 0.363 \\
\hline
\end{tabular}

Variables are presented as number of patients ( $n$ )

Data were analyzed using the chi-square test

Functional Activity Score (FAS): A, not limited (functional activity not limited because of pain); B, mild to moderate limitation (functional activity mildly to

moderately limited because of pain); $C$, severely restricted (functional activity severely limited because of pain) 
Table 3 Use of rescue analgesia in the three groups

\begin{tabular}{lllll}
\hline Variable & Group C $(\boldsymbol{n}=\mathbf{2 6})$ & Group T $(\boldsymbol{n}=\mathbf{2 6 )}$ & Group TR $(\boldsymbol{n}=\mathbf{2 6})$ & $\boldsymbol{P}$ \\
\hline Rescue analgesic & $11(42.3 \%)$ & $8(30.8 \%)$ & $2(7.7 \%)^{*}$ & 0.016 \\
\hline
\end{tabular}

Variables are presented as number of patients $\mathrm{n}(\%)$

Data were analyzed using the chi-square test

* $p<0.05$ versus Group T or Group C

Rafi et al. first described postoperative TAPB as a peripheral nerve block in 2001 [28]. Because of improvements in US technologies, anesthesiologist now commonly use US-guided TAPB for perioperative pain management $[6,18]$. A review by $\mathrm{Wu}$ et al. concluded that TAP reduced the pain score at $6 \mathrm{~h}$ after surgery and the use of analgesics at $24 \mathrm{~h}$ after surgery [29]. Walter et al. found that preoperative TAP block in patients who received laparoscopic colorectal resection led to reduced opioid use, but had no effect on pain-VAS scores and median hospital stay [30]. These results are contrary to our findings.

There may be several reasons for these contradictory results. First, laparoscopy-assisted radical resection of rectal cancer requires two incisions above the umbilicus, and there may be variations among patients in the pain arising from these incisions. There is evidence that the cephalad dermatome levels achieved by posterior TAP is at $\mathrm{T}_{10}$, which is more suitable for analgesia of the incision below the umbilicus $[8,31]$. This could explain our failure to observe a benefit from the TAP block. For upper abdominal incisions, US-guided RSB might be a better alternative for injecting local anesthetics into the posterior rectus sheath [32]. The ventral branch of the $\mathrm{T}_{7}-\mathrm{T}_{12}$ intercostal nerve can be blocked, thus anesthetizing the anterior wall of the abdomen from the xiphoid process to the pubic symphysis [33]. There is evidence that RSB blocks the anterior branch of $\mathrm{T}_{9}-\mathrm{T}_{11}$, and provides a better analgesic effect for incision around the umbilicus [34]. RSB could be performed alongside posterior TAPB to block higher dermatomes in the abdominal wall, up to $\mathrm{T}_{6}$ [22]. There is also evidence that TAPB reduces the use of fentanyl by $20 \%$, and that RSB combined with TAPB reduces the use of fentanyl by more than $60 \%$ in patients with cirrhosis undergoing liver resection [19].
A second reason for these contradictory results may be that different approaches for TAP lead to different analgesic effects. There are two major approaches used for TAP: a lateral approach and the more conventional posterior approach. In the latter approach (which we used), the US probe is placed between the costal margin and the iliac crest at the axillary midline, and then scanned backward until the transverse abdominal muscle moved into the aponeurosis. The local anesthetic is then injected into the TAP near the aponeurosis, and a wider spread of local anesthetic could provide sufficient analgesia. Previous research demonstrated that the drug spreads to the paravertebral space and creates a paravertebral block that relieves visceral pain during lower abdominal surgery $[5,35]$.

A third possible reason for the contradictory results may be that there is a lack of uniform standards regarding the doses of local anesthetics used during US-guided TAPB.

We found no significant difference in the pain-VAS score or the FAS among the three groups, because all patients used PCIA and rescue analgesics when necessary to control the pain-VAS score below 4 . There was also no significant difference in the measured recovery parameters and sufentanil-associated adverse effects among the three groups, but this may be due to the small sample size.

This study had some limitations that should be considered. First, we did not study the effect of the duration of analgesia provided by the peripheral nerve block. Previous studies showed that the analgesia duration from a single-shot TAPB lasts for 24 to $48 \mathrm{~h}$, but it is possible that our use of two nerve blocks and the poor vascularization of the TAP and RS prolonged the duration of analgesia. Second, we did not perform blood concentration monitoring because previous studies

Table 4 Recovery parameters in the three groups

\begin{tabular}{lllll}
\hline Variable & Group C $(\boldsymbol{n}=\mathbf{2 6})$ & Group T $(\boldsymbol{n}=\mathbf{2 6})$ & Group TR $(\boldsymbol{n}=\mathbf{2 6})$ & $\boldsymbol{P}$ \\
\hline Time to first flatus (h) & $63.4 \pm 8.71$ & $64.6 \pm 7.80$ & $65.6 \pm 6.35$ & 0.604 \\
Time to first solid food (h) & $81.5 \pm 7.64$ & $82.9 \pm 6.80$ & $133.1 \pm 14.73$ & $126.5 \pm 13.82$ \\
Time to first feces (h) & $132.3 \pm 13.16$ & $1(3.8 \%)$ & $2(7.7 \%)$ & 0.283 \\
Postoperative ileus & $1(3.8 \%)$ & $6.7 \pm 0.96$ & $6.8 \pm 1.08$ & 0.768 \\
Duration of postoperative hospital stay (days) & $6.5 \pm 1.01$ & & 0.590 \\
\hline
\end{tabular}

Variables are presented as mean \pm SD or number of patients $n(\%)$

Data were analyzed using a one-way analysis of variance or the chi-square test 
Table 5 Adverse effects in the three groups

\begin{tabular}{lllll}
\hline Variable & Group C $(\boldsymbol{n}=\mathbf{2 6})$ & Group T $(\boldsymbol{n}=\mathbf{2 6})$ & Group TR $(\boldsymbol{n}=\mathbf{2 6})$ & $\mathbf{P}$ \\
\hline Nausea & $5(19.2 \%)$ & $4(15.4 \%)$ & $6(23.1 \%)$ & 0.781 \\
Vomiting & $2(7.7 \%)$ & $1(3.8 \%)$ & $2(7.7 \%)$ & 0.808 \\
Puritus & $2(7.7 \%)$ & $1(3.8 \%)$ & $0(0 \%)$ & 0.353 \\
Respiratory depression & 0 & 0 & 0 & 1.000 \\
Dizziness & $3(11.5 \%)$ & $1(3.8 \%)$ & $1(3.8 \%)$ & 0.425 \\
\hline
\end{tabular}

Variables are presented as number of patients $\mathrm{n}(\%)$

Data were analyzed using the chi-square test

showed that the blood concentration of ropivacaine did not exceed the toxic threshold of $2.2 \mu \mathrm{g} / \mathrm{mL}$ when $60 \mathrm{~mL}$ of ropivacaine $0.375 \%$ was used in US-guided TAP [36, 37]. Third, the study indicated that TAPB with RSB afforded better analgesic effect than TAPB or placebo, although we did not compare the analgesic effect of RSB and TAPB. Further research on this topic is necessary. Finally, this was a single center study, so our results cannot be generalized to other medical centers.

\section{Conclusions}

In conclusion, we found that postoperative US-guided posterior TAPB with RSB significantly reduced postoperative opioid use by patients following laparoscopyassisted radical resection of rectal cancer. Further studies are required to determine the duration of analgesia provided by this procedure.

\section{Abbreviations}

PONV: Postoperative nausea and vomiting; US: Ultrasound; TAPB: Transversus abdominis plane block; RSB: Rectus sheath block; ASA: American Society of Anesthesiologists; PCA: Patient-controlled analgesia; PCIA: Patient controlled intravenous analgesia; IV: Intravenous; BIS: Bispectral index; TEM: Total mesorectal resection; CONSORT: Consolidated Standards of Reporting Trials; PACU: Post-anesthesia care unit; NRS: Numerical rating scale; APS: Acute pain service; FAS: Functional activity score

\section{Acknowledgements}

None.

\section{Authors' contributions}

$M L, Y X Y$ and $X J G$ conceived and designed the trail. ML and $X X$ collected the data. CGR and XX analyzed the data. ML, YXY and XJG wrote this paper. All authors have readed and approved the manuscript.

\section{Funding}

No funding.

\section{Availability of data and materials}

The raw data of the current study are available from the corresponding author on reasonable request.

\section{Declarations}

\section{Ethics approval and consent to participate}

Ethical approval was obtained from the institutional ethical committee of Liaocheng People's Hospital (No. 2019016). Written informed consents were obtained from participants before inclusion.

\section{Consent for publication}

Not applicable.
Competing interests

The authors declare that they have no competing interests.

\section{Author details}

${ }^{1}$ Department of Anesthesiology, Liaocheng People's Hospital, Liaocheng, Shandong, People's Republic of China. 'Department of Anesthesiology, First Affiliated Hospital, Zhejiang University School of Medicine, Hangzhou, Zhejiang, People's Republic of China.

Received: 9 September 2020 Accepted: 28 February 2021

Published online: 24 March 2021

References

1. Chen W, Zheng R, Baade PD, Zhang S, Zeng H, Bray F, Jemal A, Yu XQ, He J. Cancer statistics in China, 2015. CA Cancer J Clin. 2016;66(2):115-32.

2. Bonjer HJ, Deijen CL, Haglind E, COLOR II Study Group. A Randomized Trial of Laparoscopic versus Open Surgery for Rectal Cancer. N Engl J Med. 2015; 373(2):194.

3. Gustafsson UO, Scott MJ, Schwenk W, Demartines N, Roulin D, Francis N, CE MN, Macfie J, Liberman AS, Soop M, Hill A, Kennedy RH, Lobo DN, Fearon K, Ljungqvist O, Enhanced Recovery After Surgery (ERAS) Society, for Perioperative Care, European Society for Clinical Nutrition and Metabolism (ESPEN), International Association for Surgical Metabolism and Nutrition (IASMEN). Guidelines for perioperative care in elective colonic surgery: Enhanced Recovery After Surgery (ERAS( $\left.{ }^{(}\right)$) Society recommendations. World J Surg. 2013;37(2):259-84.

4. Levy BF, Scott MJ, Fawcett W, Fry C, Rockall TA. Randomized clinical trial of epidural, spinal or patient-controlled analgesia for patients undergoing laparoscopic colorectal surgery. Br J Surg. 2011;98(8):1068-78.

5. Yoshiyama S, Ueshima H, Sakai R, Otake H. A posterior TAP block provides more effective analgesia than a lateral TAP block in patients undergoing laparoscopic gynecologic surgery: a retrospective study. Anesthesiol Res Pract. 2016;2016:4598583.

6. Hain E, Maggiori L, Prost À la Denise J, Panis Y. Transversus abdominis plane (TAP) block in laparoscopic colorectal surgery improves postoperative pain management: a meta-analysis. Color Dis. 2018;20(4):279-87.

7. Hong S, Kim H, Park J. Analgesic effectiveness of rectus sheath block during open gastrectomy: a prospective double-blinded randomized controlled clinical trial. Medicine (Baltimore). 2019;98(15):e15159.

8. Bhatia N, Arora S, Jyotsna W, Kaur G. Comparison of posterior and subcostal approaches to ultrasound-guided transverse abdominis plane block for postoperative analgesia in laparoscopic cholecystectomy. J Clin Anesth. 2014;26(4):294-9.

9. Jeong HW, Kim CS, Choi KT, Jeong SM, Kim DH, Lee JH. Preoperative versus Postoperative Rectus Sheath Block for Acute Postoperative PainRelief after Laparoscopic Cholecystectomy: A Randomized Controlled Study. J Clin Med. 2019;8(7):1018.

10. Ren C, Xu H, Xu G, Liu L, Liu G, Zhang Z, Cao JL. Effect of intraoperative infusion of dexmedetomidine on postoperative recovery in patients undergoing endovascular interventional therapies: a prospective, randomized, controlled trial. Brain Behav. 2019;9(7):e01317.

11. Ju W, Luo X, Han B. Laparoscopic surgery is feasible for the treatment of rectal cancer after neoadjuvant chemoradiotherapy. Pak J Pharm Sci. 2016; 29(5 Suppl):1817-21.

12. Keskin M, Akici M, Ağcaoğlu O, Yeğen G, Sağlam E, Buğra D, Bulut MT, Balik E. Open versus laparoscopic surgery for rectal Cancer: single-center results of 587 cases. Surg Laparosc Endosc Percutan Tech. 2016;26(3):e62-8. 
13. Farinetti A, Bonetti LR, Migaldi M, Mattioli AV, Pennella S, Muratori S, Rossi A. A comparative analysis between laparoscopy and open colectomy: assessment of perioperative and oncological outcomes. Ann Ital Chir. 2015; 86(1):35-41.

14. Ergün M, Berkers AW, van der Jagt MF, Langenhuijsen JF, van ÖzdemirBrunschot D, van der Vliet JA, D'Ancona FC, Warlé MC. Components of pain assessment after laparoscopic donor nephrectomy. Acta Anaesthesiol Scand. 2014:58(2):219-22

15. Carmichael JC, Keller DS, Baldini G, Bordeianou L, Weiss E, Lee L, Boutros M, McClane J, Steele SR, Feldman LS. Clinical practice guideline for enhanced recovery after colon and rectal surgery from the American Society of Colon and Rectal Surgeons (ASCRS) and Society of American Gastrointestinal and Endoscopic Surgeons (SAGES). Surg Endosc. 2017:31(9):3412-36.

16. Buvanendran A, Kroin JS. Multimodal analgesia for controlling acute postoperative pain. Curr Opin Anaesthesiol. 2009;22(5):588-93.

17. Park JS, Choi GS, Kwak KH, Jung H, Jeon Y, Park S, Yeo J. Effect of local wound infiltration and transversus abdominis plane block on morphine use after laparoscopic colectomy: a nonrandomized, single-blind prospective study. J Surg Res. 2015;195(1):61-6.

18. Pirrera B, Alagna V, Lucchi A, Berti P, Gabbianelli C, Martorelli G, Mozzoni L, Ruggeri F, Ingardia A, Nardi G, Garulli G. Transversus abdominis plane (TAP) block versus thoracic epidural analgesia (TEA) in laparoscopic colon surgery in the ERAS program. Surg Endosc. 2018;32(1):376-82.

19. Yassen K, Lotfy M, Miligi A, Sallam A, Hegazi E, Afifi M. Patient-controlled analgesia with and without transverse abdominis plane and rectus sheath space block in cirrhotic patients undergoing liver resection. J Anaesthesiol Clin Pharmacol. 2019;35(1):58-64.

20. Okamoto K, Komasawa N, Kido H, Kusaka Y, Sawai T, Minami T. Efficacy of Transversus Abdominis and rectus sheath blocks in combination with continuous intravenous fentanyl for postoperative analgesia of laparoscopic colectomy: a retrospective study. Masui. 2017;66(1):73-5.

21. Tikuisis R, Miliauskas P, Lukoseviciene V, Samalavicius N, Dulskas A Zabuliene L, Zabulis V, Urboniene J. Transversus abdominis plane block for postoperative pain relief after hand-assisted laparoscopic colon surgery: a randomized, placebo-controlled clinical trial. Tech Coloproctol. 2016;20(12): 835-44.

22. Abdelsalam K, Mohamdin OW. Ultrasound-guided rectus sheath and transversus abdominis plane blocks for perioperative analgesia in upper abdominal surgery: a randomized controlled study. Saudi J Anaesth. 2016; 10(1):25-8.

23. Lu X, Yu P, Ou C, Wang J, Zhou Z, Lai R. The postoperative analgesic effect of ultrasound-guided bilateral Transversus Abdominis plane combined with rectus sheath blocks in laparoscopic hepatectomy: a randomized controlled study. Ther Clin Risk Manag. 2020;16:881-8.

24. Xu L, Hu Z, Shen J, McQuillan PM. Efficacy of US-guided transversus abdominis plane block and rectus sheath block with ropivacaine and dexmedetomidine in elderly high-risk patients. Minerva Anestesiol. 2018; 84(1):18-24

25. Shimizu R, Kawahara R, Hanada R, Okuno S, Yamasaki K, Tamai Y, Kawahara $H$. A combination of ultrasound-guided rectus sheath and transversus abdominis plane blocks is superior to either block alone for pain control after gynecological transumbilical single incision laparoscopic surgery. Clin Exp Obstet Gynecol. 2016;43(4):504-8.

26. Mugita M, Kawahara R, Tamai Y, Yamasaki K, Okuno S, Hanada R, Inaoka M, Funato T. Effectiveness of ultrasound-guided transversus abdominis plane block and rectus sheath block in pain control and recovery after gynecological transumbilical single-incision laparoscopic surgery. Clin Exp Obstet Gynecol. 2014;41(6):627-32.

27. Oh TK, Yim J, Kim J, Eom W, Lee SA, Park SC, Oh JH, Park JW, Park B, Kim $\mathrm{DH}$. Effects of preoperative ultrasound-quided transversus abdominis plane block on pain after laparoscopic surgery for colorectal cancer: a doubleblind randomized controlled trial. Surg Endosc. 2017;31(1):127-34.

28. Abdallah FW, Laffey JG, Halpern SH, Brull R. Duration of analgesic effectiveness after the posterior and lateral transversus abdominis plane block techniques for transverse lower abdominal incisions: a meta-analysis. $\mathrm{Br} J$ Anaesth. 2013;111(5):721-35.

29. Wu RC, Jensen CC, Douaiher J, Madoff RD, Kwaan MR. Transversus Abdominis plane block in laparoscopic colorectal surgery: a systematic review. Dis Colon Rectum. 2019;62(10):1248-55.

30. Walter CJ, Maxwell-Armstrong C, Pinkney TD, Conaghan PJ, Bedforth N, Gornall CB, Acheson AG. A randomised controlled trial of the efficacy of ultrasound-guided transversus abdominis plane (TAP) block in laparoscopic colorectal surgery. Surg Endosc. 2013;27(7):2366-72.

31. Hernandez MA, Vecchione T, Boretsky K. Dermatomal spread following posterior transversus abdominis plane block in pediatric patients: our initial experience. Paediatr Anaesth. 2017;27(3):300-4.

32. Osaka Y, Kashiwagi M, Nagatsuka Y, Oosaku M, Hirose C. Ultrasound-guided rectus sheath block for upper abdominal surgery. Masui. 2010;59(8):1039-41.

33. Willschke $\mathrm{H}$, Bösenberg A, Marhofer $\mathrm{P}$, Johnston S, Kettner SC, Wanzel O, Kapral S. Ultrasonography-guided rectus sheath block in paediatric anaesthesia--a new approach to an old technique. Br J Anaesth. 2006;97(2): 244-9.

34. Courreges P, Poddevin F, Lecoutre D. Para-umbilical block: a new concept for regional anaesthesia in children. Paediatr Anaesth. 1997;7(3):211-4.

35. Carney J, Finnerty O, Rauf J, Bergin D, Laffey JG, Mc Donnell JG. Studies on the spread of local anaesthetic solution in transversus abdominis plane blocks. Anaesthesia. 2011;66(11):1023-30.

36. Børglum J, Jensen $\mathrm{K}$, Christensen AF, Hoegberg LC, Johansen SS, Lönnqvist PA, Jansen T. Distribution patterns, dermatomal anesthesia, and ropivacaine serum concentrations after bilateral dual transversus abdominis plane block. Reg Anesth Pain Med. 2012;37(3):294-301.

37. Knudsen K, Beckman Suurküla M, Blomberg S, Sjövall J, Edvardsson N. Central nervous and cardiovascular effects of i.v. infusions of ropivacaine, bupivacaine and placebo in volunteers. Br J Anaesth. 1997;78(5):507-14.

\section{Publisher's Note}

Springer Nature remains neutral with regard to jurisdictional claims in published maps and institutional affiliations.
Ready to submit your research? Choose BMC and benefit from:
- fast, convenient online submission
- thorough peer review by experienced researchers in your field
- rapid publication on acceptance
- support for research data, including large and complex data types
- gold Open Access which fosters wider collaboration and increased citations
- maximum visibility for your research: over $100 \mathrm{M}$ website views per year
At BMC, research is always in progress.
Learn more biomedcentral.com/submissions 